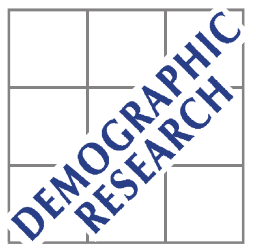

Demographic Research a free, expedited, online journal of peer-reviewed research and commentary in the population sciences published by the Max Planck Institute for Demographic Research Konrad-Zuse Str. 1, D-18057 Rostock · GERMANY www.demographic-research.org

DEMOGRAPHIC RESEARCH

VOLUME 20, ARTICLE 4, PAGES 11-36

PUBLISHED 27 JANUARY 2009

http://www.demographic-research.org/Volumes/Vol20/4/

DOI: 10.4054/DemRes.2009.20.4

Descriptive Findings

\title{
Rising marital disruption in Italy and its correlates
}

\section{Daniele Vignoli}

Irene Ferro

(C) 2009 Vignoli \& Ferro.

This open-access work is published under the terms of the Creative Commons Attribution NonCommercial License 2.0 Germany, which permits use, reproduction \& distribution in any medium for non-commercial purposes, provided the original author(s) and source are given credit.

See http:// creativecommons.org/licenses/by-nc/2.0/de/ 


\section{Table of Contents}

1 Marital dissolution in Italy: a renewed focus $\quad 12$

2 Italian marital disruption: a difficult definition for a rising trend $\quad 12$

3 The correlates of marital disruption in Italy 15

theoretical perspectives and research hypotheses

4 Data description and model specification $\quad 19$

$5 \quad$ Who dissolves the marriage in Italy? $\quad 24$

$\begin{array}{lll}6 & \text { Concluding discussion } & 27\end{array}$

$\begin{array}{llr}7 & \text { Acknowledgements } & 29\end{array}$

$\begin{array}{ll}\text { References } & 30\end{array}$ 


\title{
Rising marital disruption in Italy and its correlates
}

\author{
Daniele Vignoli ${ }^{1}$ \\ Irene Ferro ${ }^{2}$
}

\begin{abstract}
Most of our knowledge on divorce pertains to the USA and northern Europe, while demographic studies from southern Europe are relatively scarce. Our study looks at this knowledge gap through an analysis of the correlates of marital instability in Italy. We use the 2003 Italian Gender and Generation Survey, which reveals recent trends in marital disruption, including those among relatively young cohorts, and we employ event history techniques. Our results show that besides the expected correlation between marital disruption and the women's birth cohort and socio-economic status, other factors more closely linked to specific aspects of Italian society can also be identified.
\end{abstract}

${ }^{1}$ Department of Statistics “G. Parenti”, University of Florence. Email: Vignoli@ ds.unifi.it.

${ }^{2}$ Department of Statistics “G. Parenti”, University of Florence. Email: Ferro@ ds.unifi.it. 


\section{Marital dissolution in Italy: a renewed focus}

Most of our knowledge on divorce pertains to the USA and northern Europe, while demographic studies from southern Europe are relatively scarce. This is due to the fact that couple instability in southern Europe is low by developed countries' current standards. Nonetheless, marital disruption in Italy, though still not very common (Barbagli 1990; Maggioni 1990, 1997; Barbagli and Saraceno 1997, 1998; Zanatta 1997; De Rose 1999; De Rose and Rosina 1999), is now showing a marked increase. Between 1995 and 2005, the incidence of divorce rose both in absolute terms $(+75 \%)$ and in terms of rates, with the period total divorce rate climbing from 80 to 151 divorces per 1,000 (Istat 2007).

The analysis of Italian marital break-ups started to be considered "statistically" interesting about a decade after the application of the law on divorce, approved in 1970 (De Rose 2006). De Rose (1992) herself was among the first to study marital instability, using data from the retrospective "Family Structure and Behaviour Survey" of 1983. She demonstrated that women who entered into marriage younger, with better education and a full-time job, residing in large towns in the north-west of Italy, were most exposed to the risk of marital disruption. After this first pioneering study, however, the analysis of individual pathways leading to divorce as one step in the course of a woman's life did not develop consistently. This is the knowledge gap that our study intends to fill. What are the socio-demographic correlates to marital instability? Are they still the same as few decades ago (De Rose 1992)? How did improvements in women's labour market participation and empowerment impact on marriage breakdown? In order to answer these questions, we use a recent large-scale Istat survey, "Families and Social Subjects" (which also constitutes the Italian part of the Gender and Generation Survey), to which we apply event history techniques.

The paper is structured as follows. Section 2 provides an overview of trends in Italian marital disruption. Section 3 offers a theoretical elaboration on the possible correlates of Italian marital disruption. Section 4 is devoted to the data description and the model specification. The determinants of marital disruption in Italy are then scrutinized through risk models in section 5, while the final section summarizes and discusses the outcomes of the study.

\section{Italian marital disruption: a difficult definition for a rising trend}

In Italy the divorce rate cannot be used as the sole indicator of the frequency of marital dissolution. Marriage breakdown is better indicated by spousal (formal) separation, which actually breaks all links between the partners. A divorce is necessary only if one 
of them wants to marry again. In such cases (about $60 \%$ of separations) a divorce is pronounced, but only after three years of separation. For this reason, in Italy separations, not divorces, are normally considered in the study of marital conflict (e.g. Castiglioni and Dalla Zuanna 2008).

In the European context Italian marital instability seems to be an exception, because of its very low level. Nevertheless, the rise in separations is also evident in the country. In the last decades, separations have increased from 10,000 to 80,000 and, at the same time, marriages have decreased (Figure 1).

Figure 1: Trend in separations, divorces and marriages in absolute numbers in Italy, 1971-2005

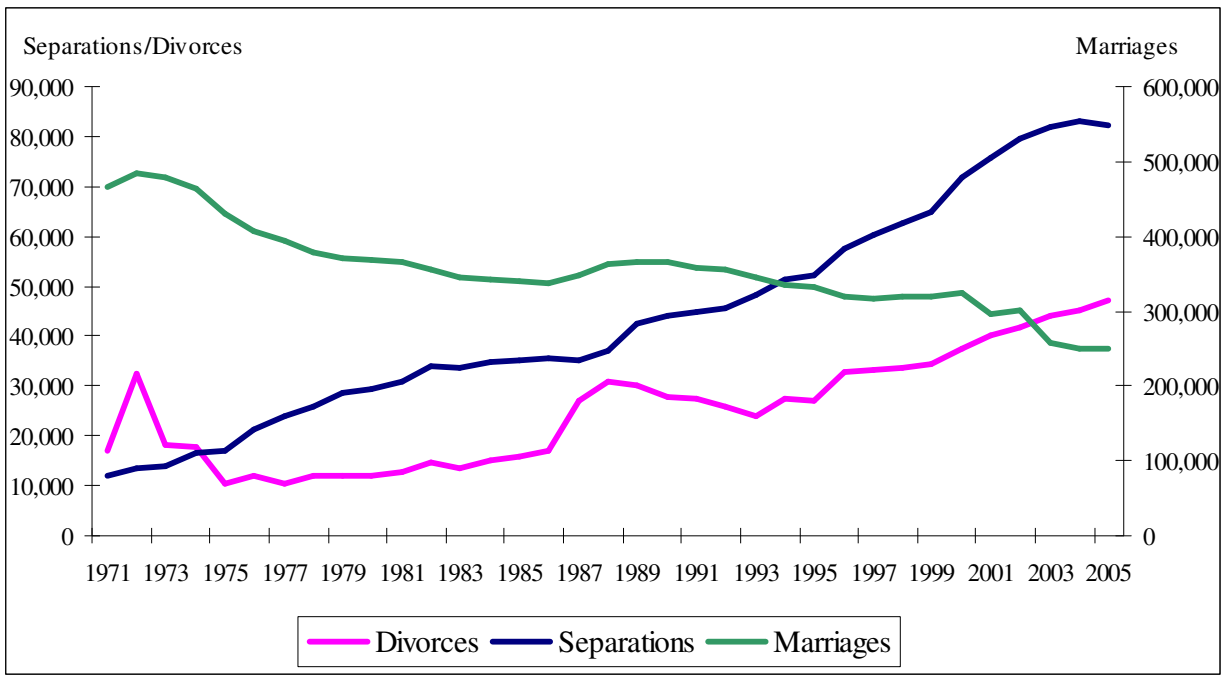

Source: Own elaboration on Istat data

Let us now move from absolute to relative numbers. We computed the Period Total (legal) Separation Rate (PTSR) and the Period Total Divorce Rate (PTDR) with respect to 1,000 marriages for the period 1971-2003 (Figure 2). PTSR and PTDR are obtained as a sum of age-specific separation rates and age-specific divorce rates respectively. Through a simplified approach (Santini 1992), the age-specific separation and divorce rates are calculated as a ratio of the number of separations and divorces in a year, $t$, according to the duration, $d$, and the average number of marriages solemnized $d$ 
years before. ${ }^{3}$ (For details see Ferro and Salvini 2007.) Both PTSR and PTDR highlight the rise in Italian marital dissolution. A faster pace of increase in PTSR compared to PTDR is also evident.

Figure 2: $\quad$ Trend in Period Total (legal) Separation Rate (PTSR) and Period Total Divorce Rate (PTDR) per 1,000 marriages in Italy, 1971-2003

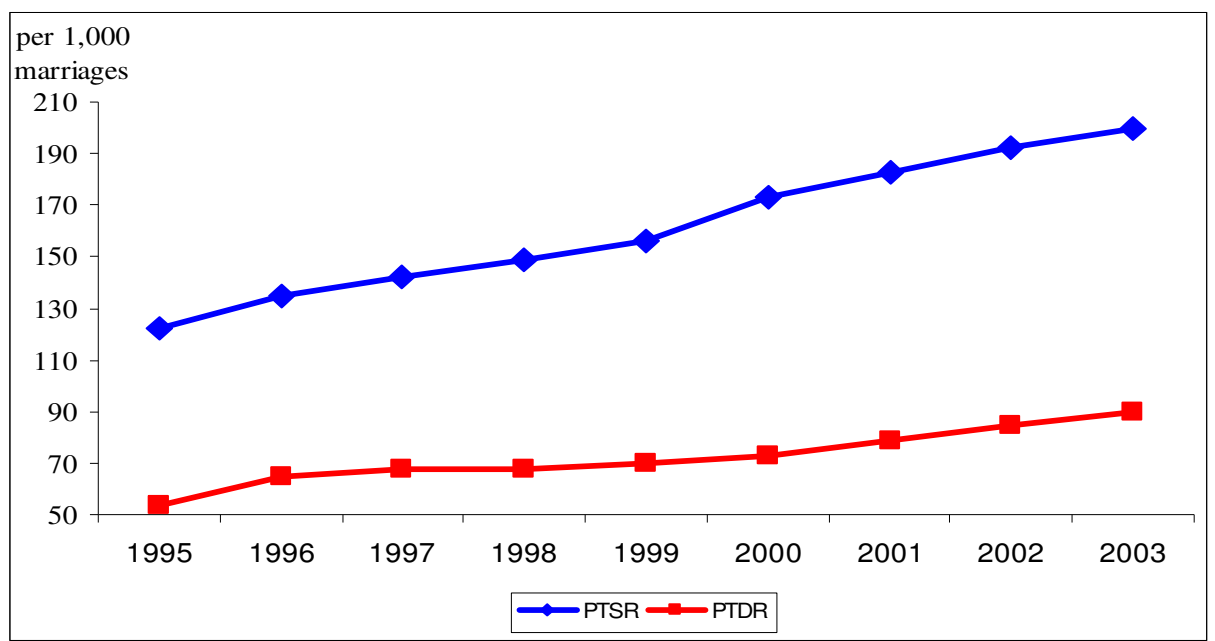

Source: Own elaboration on Istat data

There are marked differences between Italian regions with regard to marital dissolution, as with other demographic events (marriages, births). In general, separations are more common in the north and in some central regions, such as Tuscany and Lazio (Figure 3). The southern regions and Sicily have the lowest separation rates. By contrast, in the northern regions the propensity towards separation leads to levels of marital instability close to those observed in central and northern Europe (30-40\%).

\footnotetext{
${ }^{3}$ For instance, the age-specific separation rate for the year 1982 at the duration $1(d 1)$ is calculated with respect to the average number of marriages $(M)$ celebrated 1 year before. Mathematically:

$s^{182, d 1}=S_{82}^{d 1} /\left[M_{80}+M_{81}\right] \cdot 0,5$.
} 
Figure 3: Period Total (legal) Separation Rate per 1,000 marriages in Italian regions, 2003

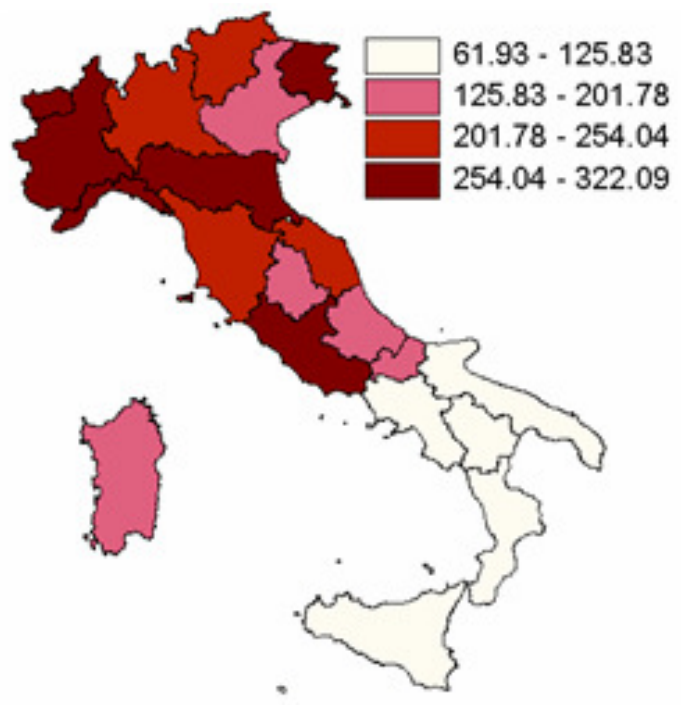

Source: Own elaboration on Istat data

Note: The categories are formed on the basis of the natural breaks method (Jenks 1963)

\section{The correlates of marital disruption in Italy: theoretical perspectives and research hypotheses}

There is general agreement that the connection between new demographic behaviour and changing values lies at the heart of the recent demographic history of Europe, characterized by the diversification of family formation and childbearing patterns (van de Kaa 1987; Lesthaeghe 1992). According to the theory of the "ideational shifts" (Preston 1986), the diffusion of new ways of living as a couple relates to increased individual autonomy in the ethical, political, and religious spheres, or, in other words, to the increase in acceptance of subjective values across the generations. The cultural dimension has therefore influenced the degree of experimentation in various forms of union among the youngest cohorts of women, who, we expect, should present higher dissolution levels.

In addition to the general revolution in customs and habits, we believe that the behaviour of younger women has also been influenced by the change in the Italian 
divorce normative setting. From 1865 to 1970, under the Civil Code, marriage could end only with the death of one of the partners. With Law no 898 of 1 December 1970, divorce was established in Italy. Five years later, in 1975, the possibility of requesting judicial separation without the consent of both parties was introduced. Another reform, of 1 August 1978, improved the economic protection of the weaker partner. Since 1987 three years of separation instead of five, as was formerly the case, have been enough to apply for a divorce. In line with De Rose and Di Cesare (2003), we hypothesize that the introduction of more liberal norms for obtaining a divorce is positively associated with marital dissolution risk.

The still-low levels of Italian marital disruption are often linked to the pressure imposed by Catholic values (Sgritta 1993). We expect, in this sense, separation to be more widespread among non-practising Catholic women. In order to test this hypothesis, we focus on selected characteristics that are believed to be valid markers of individual principles and a propensity to accept the possibility of union dissolution. In this sense, the decision to cohabit before marriage or to take one's vows in a register office instead of in church is a sign of a low level of religious attachment.

As for premarital cohabitation, two different arguments can be put forward. On the one hand, premarital cohabitation is seen as helping to stabilize subsequent married relationships, since those women who cohabit gain more information about their spouse than those who do not, and only cohabiting couples who find themselves well suited will decide to marry, thus weeding out unsuccessful partnerships. On the other hand, it may be the case that premarital cohabitation is a manifestation of secularized values and convictions, possibly implying an increased risk of dissolution. We expect a positive association between premarital cohabitation and marital dissolution in Italy. Starting the union with cohabitation followed by marriage, rather than directly entering into marriage, has a strong effect on union instability. According to Hoem and Hoem (1992), direct marriage might be a manifestation of particular religious or other convictions, as a consequence of which a decrease in the dissolution risk for this cluster of women is to be expected. In line with Lillard et al. (1995), we believe that there might be unobserved differences between individuals, such as attitudes and values, which make those who are most likely to cohabit before marriage also most likely to end their (unhappy) marriage with a separation.

The literature provides several arguments for the positive relationship between parents' divorces and those of their offspring (for an overview, see Engelhardt et al. 2002). This can be an effect of the transmission of behaviour or, alternatively, a tendency by women to behave in ways considered "acceptable" by her parents (e.g. Cherlin et al. 1995; Berrington and Diamond 1999; Kiernan and Cherlin 1999). It may also be the case that children of parents who divorce early get more information on how the divorce process can be handled (Lyngstad 2004). We therefore expect a strong 
positive correlation between divorced parents and divorced offspring in Italy. This hypothesis is particularly convincing in the Italian context because of a possible vertical diffusion of family patterns. According to the literature, in fact, Italy shares with other southern European countries the "strong" family model (Reher 1998). Micheli (2000) and Dalla Zuanna (2001) emphasize the role of familism in shaping family and fertility choices.

An additional aspect concerning family background is the parents' educational level. Again we expect a positive matching between divorce risk and family background. Hoem and Hoem (1992) suggest that there may be something in the upper and middle classes that makes dissolution an acceptable possibility when a union does not function as desired. Highly educated parents may even facilitate a divorce (Lyngstad 2004): for example, if their divorcing daughter's own income is not enough to afford legal assistance during the separation process, or to establish a new household.

The impact of childbearing on union dissolution is also important, although the evidence is mixed. The presence of children seems to consolidate the union (White 1990; De Rose 1992; Hoem and Hoem 1992; Goode 1993; Tzeng and Mare 1995; Weiss and Willis 1997; Berrington and Diamond 1999; Jalovaara 2001; Coppola and Di Cesare 2008). Becker et al. (1977), for instance, observe that children are maritalspecific capital and, consequently, they should reduce the risk of divorce. It is true, however, that a few studies using data from the United Kingdom have documented that during the 1990s children had a destabilizing effect on unions (Boheim and Ermisch 1999; Chan and Halpin 2001). Here, though, we view a child as a sign of family harmony, associated with a low dissolution risk. Moreover, not only the number but also the ages of the children represent an essential predictor of divorce risk. People may be reluctant to separate when they have a young child. Rates of divorce have been found to be lowest when the child is young; then, as the child grows older, the risk of separation rises again (e.g. Andersson 1997).

The influence of education on the risk of divorce is theoretically ambiguous. Becker et al. (1977) and Becker (1981) argue that highly educated men tend to marry highly educated women and less educated men tend to marry less educated women. In this framework, union formation is viewed as a process in which actors compete to find the best partner, where "best" means "with the highest education". A couple with at least one spouse who has had a higher education will therefore benefit more from marriage in comparison with the others. However, the link between women's education and divorce risk can also signal the opposite effect. A wife who has had a good education has better labour market prospects and earning potential than a wife who has not. Therefore, she will also "specialize" less in family-specific activities (household chores) and will have less to lose from a marriage breakdown. Thus, in general, the connection between women's education and family instability is likely to be different in 
different societies. A positive relationship between educational attainment and divorce risk was found, for example, for the United States by Ono (1998) and for the Netherlands by Poortman and Kalmijn (2002). However, most of the research on this topic suggests a negative association for the Nordic countries (Kravdal and Noack 1989; Hoem 1997; Jalovaara 2001, 2003; Lyngstad 2004). A negative association was also observed in Italy (De Rose 1992).

Women's employment increases their independence and, as a result, the risk of marital disruption, whether by overthrowing traditional marriage norms, by facilitating divorce in case of conflicts in the relationship because women are better able economically to cope with family breakdown, or by taking women away from their traditional responsibilities at home, which in turn generates conflict between the spouses (Ross and Sawhill 1975; Moore and Waite 1981; Spitze and South 1985; Heckert et al. 1998; Ono 1998; Oláh 2001). In short, documented findings view women's work as a pivotal aspect that destabilizes marriages. This is true even in Sweden, where female participation in the labour force is high, but wives who work full-time have higher rates of first-marriage disruptions (Hoem and Hoem 1992; Trussell et al. 1992). An Australian study also reported higher rates of marital disruption for employed wives (Bracher et al. 1993). Throughout an analysis based on Swedish registered data for the period 1981-98, Liu and Vikat (2004: 14) confirm: "We found strong support for the independence effect hypothesis, as the divorce risk increased linearly with the share of the wife's income in the couple's total income." The findings of Liu and Vikat are consistent with those of Jalovaara (2003) for Finland, another "modern" country with respect to female autonomy. However, the evidence referring to the effect of wives' income and the income ratio on the risk on marital disruption is less consistent (e.g. Greenstein 1990, 1995; Oppenheimer 1997; Sayer and Bianchi 2000; Liu and Vikat 2004).

As for Italy, De Sandre (1980) was the first to show the increase in marital instability among women with high socio-economic status in the first half of the 1970s. That finding was later confirmed by Corsini and Ventisette (1988), still on aggregate data, and by De Rose (1992) on micro data. The latter author concluded that the modest diffusion of family dissolution in Italy can certainly be explained, at least in part, by the delay in the changing status of women (such as high standards of education, qualified occupational activities, a greater independence from the roles of mother and wife). It is worth remembering that Italy has a relatively low female labour force participation rate (FLFP). In 1990, the FLFP rate for the central age group 25-54 was 54\%, compared to a EU-15 mean rate of 64\%. According to the OECD Employment Outlook (2005), Italy's FLFP rate rose to $64 \%$ in 2004, but its relative position had not changed much (the EU-15 FLFP rate in the 25-54 age group had climbed to $76 \%$ by then). 
Blossfeld et al. (1995) argue that the link between women's socio-economic status and marriage dissolution appears weaker as the family system becomes less traditional and more heterogeneous. Italy is at an early stage in the process of diffusion of new family patterns. Women's socio-economic status is, therefore, expected to be a potent explanatory factor of marriage breakdown in the Italian context: it is natural to anticipate that the higher the economic status the woman has, the more likely it is that she will separate. Women with a secure salary will find it easier to afford the expense of establishing a separate home and to deal with other financial difficulties related to the marriage dissolution, as well as being better able to face the prospect of a "new start". Moreover, a positive correlation between education and divorce in Italy is also hypothesized, assuming that a woman's educational attainment represents a valid marker of a professional job as well as her wage. In short, we expect the impact of women's socio-economic status on marital disruption to be particularly relevant in the Italian context, where tradition dominates in terms of both gender roles and gender ideology.

\section{Data description and model specification}

The study uses recent micro data, known as "Families and Social Subjects" 2003, an Istat survey that constitutes the Italian part of the Gender and Generation Survey. The FSS 2003 is a retrospective survey, conducted in November 2003, with the aim of studying the effects of various background characteristics on the rate of marital dissolution.

In this research the event of interest is a woman's first marriage separation. We extend the concept of legal separation (see section 2) to include de facto separations: that is, separations not yet accompanied by a legal provision (De Rose 1992). We include de facto separation in the analysis because this is the moment that marks the dissolution of marriage for all of the three possible categories of separated people: de facto separated, judicially separated and divorced. In many cases, however, the date of this event is missing, so in order to give more robustness to the analysis we proceed with an imputation system as follows. Women who declared the date of both the de facto and the legal separation were considered, and the length of time between these two events was estimated according to three sub-groups of women clustered by age and marital status. This estimation was used to calculate the dates of de facto separation for those women for whom information was missing. ${ }^{4}$

\footnotetext{
${ }^{4}$ We estimated 258 additional de facto separations.
} 
The analysis is conducted from a life-course perspective and an event history model is employed to measure the risk of separation. This is made possible by the design of the questionnaire, which contains information on employment, partnership, and fertility histories. A woman's separation risk is defined as the probability of experiencing de facto separation given her individual characteristics. For the specification of the baseline risk, a piecewise constant function is chosen. The risks are assumed to be constant within each defined time period, but they may vary across such periods. The baseline duration is recorded by the month, which is also employed as a time unit for the other considered time-varying events. We estimated the model before and after the imputation system: minor changes proved that the imputation system did not introduce any bias in the model estimates.

In order to account for the research hypotheses put forward in the previous section, the following variables are used to specify the model. As for birth cohorts, we introduced the following into the model: 1938-54, 1955-64, and 1965-83 (note that this last cohort has never been studied previously, to the best of our knowledge). Moreover, a calendar-period covariate is included, so as to capture the influence of changes in the Italian normative environment on marital dissolution intensity. Conversely, changes in legal regulations may reflect ongoing changes in attitude and behaviour when the law-giver recognizes those changes, and a change in law influences changes in behaviour only when it has come into force. Therefore, in order to catch any changes in behaviour shortly before the change in the divorce law and after it, three time periods are considered in the model: before 1982, January 1983-March 1987, and after March 1987.

The area of residence is also included in the model, so as to control for the wellknown north-south differences in the Italian marital dissolution pattern (Ferro and Salvini 2007). Unfortunately, this information was collected at the time of the interview, which introduces the risk of performing a so-called "anticipatory analysis" (Hoem and Kreyenfeld 2006a, 2006b). However, Italian internal mobility has been low in the last decades and was mainly confined in short distances (Tomassini et al. 2003). We therefore decided to include a covariate describing the macro-region of residence: North, Centre, and South and Islands.

In order to account for women's religiosity we tested the impact of the rite of marriage (a dichotomous variable to see whether the wedding was celebrated in the register office or in the church) and the experience of premarital cohabitation (also dichotomous). Other variables of interest in studying the pattern of separation are those related to family background. ${ }^{5}$ In this paper, we consider the educational level (low or

\footnotetext{
${ }^{5}$ It would have been interesting to also test parents' religiosity, but this information was not collected in the survey.
} 
medium-high) of women's parents and a dichotomous variable relating to parental marriage dissolution.

We also considered a variable describing the impact of children on the risk of marital disruption. We distinguished between childless, parity 1 with child aged 0-6 years, parity 1 with child aged 7 years or more, parity 2 or higher with youngest child aged $0-6$ years, and parity 2 or higher with youngest child aged 7 years or more.

Finally we included women's socio-economic status in the model, measured in terms of educational attainment and labour market participation. Using information referring to the highest educational level ever reached, we clustered educational attainments in three groups: low education (no schooling and primary school), medium education (high-school qualification), and high education (degree qualification and higher education). There could be objections on the basis that it would have been more convenient to use education as a time-varying covariate (Hoem 1996; Hoem et al. 2001). Nevertheless, the inclusion of the highest level of education ever reached is justified by the particular Italian pattern of family formation. People normally tend to form a family only after completing their education and training period (Ongaro 2002). Thus it is relatively trouble-free to use the highest educational level, since most respondents have completed their studies by the time of union formation and especially before marital disruption. In terms of women's economic independence, our data set does not provide information on income. Therefore a wife's employment status ${ }^{6}$ is used as a proxy of her economic autonomy. As for job specification, it is possible to disentangle the time-varying covariate referring to the employment status of women according to the change in the type of job over time (not working; working in a temporary job; working in a permanent job). "Permanent job" represents a very heterogeneous group that also includes self-employed people. Unfortunately, it is not possible to disentangle this particular group during the life course, as detailed information was not available. "Not working" is also a broad classification that includes both unemployed and inactive women.

The analysis focuses on the possible influence of women's work on marital instability. Our aim, however, is merely to verify a possible association between the two phenomena. The direction of the causal link between employment and divorce is, in fact, unclear. Women whose marriages are unhappy may, in some cases, decide to enter the labour market because of their need to cope with a divorce which, they sense, is

\footnotetext{
${ }^{6}$ As demonstrated in extensive literature (for an overview see Matysiak and Vignoli 2008; Matysiak and Vignoli, forthcoming), job and fertility histories could be interrelated. The inclusion of both dimensions in the same statistical model is therefore problematic. However, a separate analysis of the two aspects reveals that the influence on marital dissolution is the same whether the two variables are inserted together or not.

${ }^{7}$ It would have been interesting to use women's working hours instead of the type of contract. The former variable, however, was not collected in a dynamic perspective in the survey, which makes it impossible to use within an event history framework.
} 
approaching. Indeed, if a woman starts a job just prior to a separation, the separation is probably the underlying cause of her new labour activity. Therefore, just as De Rose (1992) did, we classify as unoccupied women who started to work only one year before the separation. ${ }^{8}$

Unfortunately, we do not have information on the former partner that could be used as a correlate. We selected a sub-sample of 7,594 women, of which 592 experienced a de facto separation. The overall composition of our sample is presented in Table 1, which includes exposure time (women-months observed in marriages) and events (separations) by each of the variables used in the modelling procedure.

Table 1: Progression to separation in Italy: exposure and events in the study population

\begin{tabular}{lrrrr}
\hline & Women-months observed in marriages & \multicolumn{2}{c}{ Separations } \\
\cline { 2 - 5 } Covariates & Abs. Val. & $\%$ & Abs. Val. & $\%$ \\
\hline Birth cohort & $1,268,442$ & 64.0 & 218 & 36.8 \\
$1938-54$ & 518,771 & 26.1 & 242 & 40.9 \\
$1955-64$ & 195,527 & 9.9 & 132 & 22.3 \\
1965-83 & & & & \\
Calendar period & & 23.8 & 61 & 10.3 \\
Before 1982 & 471,049 & 13.3 & 75 & 12.7 \\
1983-March 1987 & 265,495 & 62.9 & 456 & 77.0 \\
After March 1987 & $1,246,196$ & & & \\
Region of residence & & 51.0 & 369 & 62.3 \\
North & $1,012,884$ & 20.3 & 108 & 18.2 \\
Centre & 401,672 & 28.7 & 115 & 19.5 \\
South and Islands & 568,183 & & & \\
Mother's educational level & & 89.9 & 504 & 85.1 \\
Low & $1,783,278$ & 10.1 & 88 & 14.9 \\
Medium-high & 199,461 & & & \\
\hline
\end{tabular}

${ }^{8}$ This decision resulted in 71 changes of work status (9\% of cases). Apparently, it does not affect our estimates, which we tested both with and without this restrictive assumption. However, for the theoretical reasons discussed in the text, we decided to preserve this option. 
Table 1: (continued)

\begin{tabular}{|c|c|c|c|c|}
\hline \multirow[b]{2}{*}{ Covariates } & \multicolumn{2}{|c|}{ Women-months observed in marriages } & \multicolumn{2}{|c|}{ Separations } \\
\hline & Abs. Val. & $\%$ & Abs. Val. & $\%$ \\
\hline \multicolumn{5}{|c|}{ Father's educational level } \\
\hline Low & $1,708,633$ & 86.2 & 471 & 79.6 \\
\hline Medium-high & 274,107 & 13.8 & 121 & 20.4 \\
\hline \multicolumn{5}{|l|}{ Parents' divorced } \\
\hline No & $1,939,895$ & 97.8 & 398 & 67.1 \\
\hline Yes & 42,845 & 2.2 & 29 & 4.9 \\
\hline \multicolumn{5}{|l|}{ Premarital cohabitation } \\
\hline No & $1,907,051$ & 96.2 & 523 & 88.3 \\
\hline Yes & 75,689 & 3.8 & 69 & 11.7 \\
\hline \multicolumn{5}{|l|}{ Rite of wedding } \\
\hline Civil & 179,280 & 9.0 & 117 & 19.8 \\
\hline Religious & $1,803,460$ & 91.0 & 475 & 80.2 \\
\hline \multicolumn{5}{|l|}{ Number of children* } \\
\hline Childless & 278,767 & 14.1 & 152 & 25.7 \\
\hline 1 (aged 0-6) & 327,060 & 16.5 & 105 & 17.7 \\
\hline 1 (aged 7+) & 295,104 & 14.9 & 118 & 19.9 \\
\hline $2+($ youngest aged $0-6)$ & 379,580 & 19.1 & 74 & 12.5 \\
\hline $2+($ youngest aged $7+)$ & 702,228 & 35.4 & 143 & 24.2 \\
\hline \multicolumn{5}{|l|}{ Educational level } \\
\hline Low & $1,226,798$ & 61.9 & 253 & 42.7 \\
\hline Medium & 594,612 & 30.0 & 274 & 46.3 \\
\hline High & 161,329 & 8.1 & 65 & 11.0 \\
\hline \multicolumn{5}{|l|}{ Employment status* } \\
\hline No work & 595,807 & 30.0 & 122 & 20.6 \\
\hline Temporary job & 303,763 & 15.4 & 89 & 15.0 \\
\hline Permanent job & $1,083,170$ & 54.6 & 381 & 64.4 \\
\hline Total & $1,982,740$ & & 592 & \\
\hline
\end{tabular}

*Time-varying covariate 


\section{Who dissolves the marriage in Italy?}

The factors associated with separation risk are presented in Table 2. The model parameters, produced as maximum-likelihood estimates, are shown in the form of relative risks, together with their standard errors and p-values. ${ }^{9}$

As discussed before, the birth cohort of women was included to account for the patterns of temporal increase in separation risks for the youngest cohorts. The trend may reflect the greater diffusion and acceptance of a more flexible type of union among new generations, given their exposure to the general revolution of ideals and norms governing social living patterns. The distance between the older and the younger cohorts is, in fact, remarkable: the risk of separation is almost three times as high for the cohorts of women born between 1965 and 1983 as for those born between 1938 and 1954. This represents perhaps the clearest manifestation of ideational and cultural transformation, as well as the spread of new ideas and values regarding the family that have evidently changed the attitudes of the Italian younger generation towards conjugal life. In addition, we considered the period variable in order to take into account the introduction of the reform of 1987. Indeed, the risk of marital dissolution rises by about $40 \%$ after 1987. Note, though, that the risk of marriage breakdown was already increasing in the period shortly before the modification of the law. So it is not only the change in the law itself that needs to be considered, because the "new" pattern was already spreading before.

Looking at the area of residence, the well-known north-south differential emerges clearly from our estimates. In comparison with the women who live in the north, the risk of a separation decreases by $22 \%$ in the centre and by $36 \%$ in the mezzogiorno. In Italy, therefore, the socio-economic and cultural conditions of the environment in which the woman lives still constitute potent factors in determining the risk of separation.

In considering the women's family background, the study focuses first on their parents' education. The results of the analysis show that women with well-educated parents do not present a significantly higher risk of separation than the others. Conversely, those who experienced a parental dissolution are most likely to separate. In other words, women with divorced parents may feel greater approval for their own divorce than the others.

As for the characteristics of marriage, the couples who experienced premarital cohabitation are more likely to end up divorced: the risk is about $82 \%$ higher. We are not claiming that premarital cohabitation causes divorce. It may well be that there are unobserved differences between individuals, such as attitudes and values, which make both cohabitation and divorce more likely. We also considered whether the marriage was solemnized in a religious or a civil ceremony. Civil marriages are more likely to

\footnotetext{
${ }^{9}$ We also fitted several models with interaction terms which proved negligible (results not shown here).
} 
experience a breakdown than religious ones (the risk is $70 \%$ higher). Hence individuals who choose civil marriage may be characterized by more secularized values.

The presence of the first child increases the stability of Italian families while the baby is relatively young. As the child grows older, marriage stability does not vary significantly. Furthermore, we also get the usual - and theoretically expected - results that additional children lower the risk of marital breakdown and that risk is lowest when the child is relatively young.

Finally the personal socio-economic situation of a woman, measured here through her labour market position and her educational level, is pivotal in determining the risk of separation. Women in employment, either temporary or permanent, are roughly twice as likely to separate as non-working women. This result confirms our hypothesis that the union instability is closely related to new forms of behaviour and habits accessible to women. The influence of women's education also proceeds in the expected direction and further corroborates the findings related to women's employment status. The model outcomes demonstrate that the dissolution risk increases with the woman's educational level: by $31 \%$, passing from low to high education. This result shows that a lack of education appears to be an obstacle for women wishing to separate from their husbands.

Table 2: Correlates of marriage dissolution risk in Italy: event history model for the event "de facto separation"

\begin{tabular}{lccc}
\hline & Relative risk & Standard error & P-value \\
\hline $\begin{array}{l}\text { Years elapsed since marriage } \\
\text { (baseline duration) }\end{array}$ & & & \\
$0-1$ & 1 & & \\
$2-3$ & 1.59 & 0.297 & 0.013 \\
$4-5$ & 1.84 & 0.363 & 0.002 \\
$6-7$ & 1.94 & 0.402 & 0.001 \\
$8-10$ & 2.29 & 0.488 & 0.000 \\
$11-14$ & 2.05 & 0.420 & 0.000 \\
$15+$ & 1.38 & 0.389 & 0.250 \\
Cohort & & & \\
$1938-54$ & 1 & & 0.000 \\
$1955-64$ & 1.87 & 0.220 & 0.000 \\
$1965-83$ & 2.64 & 0.428 & \\
\hline
\end{tabular}


Vignoli \& Ferro: Rising marital disruption in Italy and its correlates

Table 2: (continued)

\begin{tabular}{|c|c|c|c|}
\hline & Relative risk & Standard error & P-value \\
\hline \multicolumn{4}{|l|}{ Calendar period $^{\star}$} \\
\hline Before 1982 & 1 & & \\
\hline 1983- March 1987 & 1.49 & 0.270 & 0.029 \\
\hline After March 1987 & 1.42 & 0.250 & 0.048 \\
\hline \multicolumn{4}{|l|}{ Region of residence } \\
\hline North & 1 & & \\
\hline Centre & 0.78 & 0.086 & 0.023 \\
\hline South and Islands & 0.64 & 0.070 & 0.000 \\
\hline \multicolumn{4}{|c|}{ Mother's educational level } \\
\hline Low & 1 & & \\
\hline Medium-high & 1.09 & 0.167 & 0.581 \\
\hline \multicolumn{4}{|c|}{ Father's educational level } \\
\hline Low & 1 & & \\
\hline Medium-high & 1.21 & 0.166 & 0.169 \\
\hline \multicolumn{4}{|l|}{ Parents' divorced } \\
\hline No & 1 & & \\
\hline Yes & 1.48 & 0.301 & 0.054 \\
\hline \multicolumn{4}{|l|}{ Premarital cohabitation } \\
\hline No & 1 & & \\
\hline Yes & 1.82 & 0.255 & 0.000 \\
\hline \multicolumn{4}{|l|}{ Marriage rite } \\
\hline Religious & 1 & & \\
\hline Civil & 1.70 & 0.190 & 0.000 \\
\hline \multicolumn{4}{|c|}{ Number and age of children* } \\
\hline Childless & 1 & & \\
\hline 1 (aged 0-6) & 0.57 & 0.079 & 0.000 \\
\hline 1 (aged 7+) & 0.83 & 0.131 & 0.230 \\
\hline $2+($ youngest aged $0-6)$ & 0.38 & 0.061 & 0.000 \\
\hline $2+$ (youngest aged 7+) & 0.56 & 0.092 & 0.000 \\
\hline \multicolumn{4}{|l|}{ Educational level } \\
\hline Low & 1 & & \\
\hline Medium & 1.29 & 0.199 & 0.100 \\
\hline High & 1.44 & 0.136 & 0.000 \\
\hline \multicolumn{4}{|l|}{ Employment status ${ }^{\star}$} \\
\hline No work & 1 & & \\
\hline Temporary job & 1.88 & 0.228 & 0.000 \\
\hline Permanent job & 1.97 & 0.283 & 0.000 \\
\hline
\end{tabular}




\section{Concluding discussion}

This study aims to add to our understanding of general patterns of divorce through an analysis of the correlates of Italian marital instability, employing a large-scale sample taken from the 2003 Italian Gender and Generation Survey. This survey allows us to capture recent trends in marital disruption, including those among relatively young cohorts.

As expected, our findings demonstrate that women born in the most recent decades are subject to a high risk of marital separation, higher than women with any other characteristics considered in the analysis. Moreover, women's employment status has a very strong positive impact on marital disruption. The risk of divorce among employed women (both temporary and permanent workers) is almost twice as high as for those who do not work. This may be interpreted as one result of their increased independence: receiving an income or having earning power lowers a wife's constraint to stay in an unhappy marriage. Thus a woman's degree of economic autonomy is a pivotal factor in her ability to handle a separation. Women's work may also represent a destabilizing element on the traditional roles played by couples.

Education is also an important variable, with separations more frequent for women with a degree. Education may be linked to better economic prospects, which then reduce the relative benefits of traditional gender roles within marriage and will help women to gain economic independence, offering better job opportunities. Blossfeld et al. (1995: 219) found that as family arrangements became less traditional and more heterogeneous, women's education also became less connected to divorce. Looking at the Italian context, the risk of marriage disruption still increases with a woman's educational attainment, possibly because she is then better able to dissolve an unhappy marriage in violation of an established social norm. It suggests that the status of women and the family system in Italy are still quite "conventional", despite the fact that the family system is becoming more flexible.

The role of women's birth cohort and their socio-economic status accords with the study's research hypotheses. However, arguments that the marked rise in Italian family instability is a reaction to the spread of new ideas, attitudes, and value orientation among the younger generation - as well as to increased employment and independence among women - may not tell the whole story. Other correlates contributing to marital dissolution that are more intimately related to the specific Italian situation can also be identified.

The significance of religious values can be alluded to. This may in part be illustrated by the effects on the rite of marriage and premarital cohabitation: the incidence of both phenomena rose markedly during the 1990s. Specifically our results suggest that those who married in a civil ceremony or experienced cohabitation before 
marriage may already hold more secularized values, exhibiting a higher family dissolution risk. Incidentally this finding also confirms that Catholic values still play a significant role in the determining marital customs in Italy.

Another specific feature of Italian society is embedded in the relatively complex legal procedure which is required to obtain a divorce. Our analysis has shown that the 1987 law assisted the inclination to union dissolution by simplifying and accelerating the process of getting divorced. We may therefore suppose that the still relatively low levels of separation in Italy are linked to the complex normative climate. A further simplification of the present law might increase divorce among people wishing to end an unhappy marriage. In a recent paper Castiglioni and Dalla Zuanna (2008) show that legal separation will become increasingly frequent over the coming years for all marriage cohorts. From this perspective we may desire a further modification in the law, with the aim of making divorce easier and quicker, in order to recognize the ongoing new Italian divorce dynamics.

This study is not without limitations. The major drawback of this paper is the absence of a "couple perspective". This has led to a possible overestimation of the correlation between women's employment and divorce risk. In other words, the influence of the so-called "Independence Effect" may be mitigated when the gender ideology of the couple is also considered (Sayer and Bianchi 2000). In a modern society gender ideology has become more egalitarian and, as a consequence, so has the role of both partners in the labour market. Therefore the equal income of both partners should stabilize rather than destabilize marriage. However, it must be said that men's and women's roles in the labour market are still far from being egalitarian in Italy. So we believe that our results are credible, even if probably partly biased towards an overestimation of the correlation between women's socio-economic status and marital dissolution risk. Furthermore, Sayer and Bianchi (2000) also stress that marital commitment and happiness are better predictors of marital dissolution than economic independence. A wife's labour market participation may measure only the role of her economic independence in ending a bad marriage, and not apply across all marriages.

To conclude, we are aware that many variables employed in our study might raise selection and endogeneity issues. We are, in fact, far from disentangling causal relationships between the risk of marital dissolution and the selected covariates. We are mainly aiming to provide a general framework for the correlates of Italian marital instability. This may suggest useful avenues for further research. Indeed, many of the associations found here may represent the objective of further analysis employing methodological techniques in order to extricate causal relationships.

All in all, implications for future research are to seek a richer data set which would provide longitudinal measures of couples' marital satisfaction as well as couples' gender roles and ideology. 


\section{Acknowledgements}

This research was supported by the Italian MiUR PRIN grant "Family Instability: Causal Aspects and Demographic, Economic, and Social Consequences", coordinated by Massimo Livi Bacci (2005) and Letizia Mencarini (2006). We are indebted to Gustavo De Santis, Anna Matysiak, Fabrizia Mealli, and Silvana Salvini for valuable comments on earlier drafts. We also wish to acknowledge the constructive comments of two anonymous reviewers of this journal which, in our view, significantly improved the paper. 


\section{References}

Andersson, G. (1997). The Impact of Children on Divorce Risks of Swedish Women. European Journal of Population 13: 109-145 doi:10.1023/A:1005803001129

Barbagli, M. (1990). Provando e riprovando. Matrimonio, famiglia e divorzio in Italia $e$ in altri paesi occidentali. Bologna: Il Mulino.

Barbagli, M. and Saraceno C. (1997). Lo stato delle famiglie in Italia. Bologna: Il Mulino.

Barbagli M. and Saraceno C. (1998). Separarsi in Italia. Bologna: Il Mulino.

Becker, G. S., Landes, E. M., and Michael, R. T. (1977). An economic analysis of marital instability. Journal of Political Economy 85: 1141-1188. doi:10.1086/260631.

Becker, G.S. (1981). A treatise on the family. Cambridge: Harvard University Press.

Berrington, A. and Diamond, I. (1999). Marital disruption among the 1958 British birth cohort: The role of cohabitation. Population Studies 53: 19-38. doi:10.1080/00324720308066

Blossfeld, H.-P., De Rose, A., Hoem, J. M., and Rohwer G. (1995). Education, modernization, and the risk of marriage disruption: differences in the effect of women's educational attainment in Sweden, West-Germany, and Italy. In: Mason., K.O. and Jensen, A.-M. (eds.). Gender and Family Change in Industrialized Countries. Oxford: Clarendon Press for the IUSSP.

Boheim, R. and Ermisch, J. (1999). Breaking up-Financial surprises and partnership dissolution. Colchester: University of Essex (ISER Working Papers; WP-19999).

Bracher, M., Santow, G., Morgan, S. P., and Trussell, J. (1993). Marriage Dissolution in Australia: Models and Explanations. Population Studies 47: 403-25. doi:10.1080/0032472031000147216.

Castiglioni, M. and Dalla Zuanna, G. (2008). Analyse des séparations légales par promotions de mariages en Italie. Population-F 63(1):177-198.

Chan, T. W. and Halpin, B. (2001). Divorce in the UK. Oxford: University of Oxford (Department of Sociology Working Paper; WP-2001-01). 
Cherlin, A., Kiernan, K., and Chase-Lansdale, L. P. (1995). Parental divorce in childhood and demographic outcomes in young adulthood. Demography 32(3): 299-318. doi: $10.2307 / 2061682$

Coppola, L. and Di Cesare, M. C. (2008). How fertility and union stability interact in shaping new family patterns in Italy and Spain. Demographic Research18(4): 117-144. http://www.demographic-research.org/Volumes/Vol18/4. doi:10.4054/DemRes.2008.18.4.

Corsini, C. and Ventisette, M. (1988). Separazioni e Divorzi. Secondo rapporto sulla situazione demografica in Italia. Rome: Istituto di Ricerche sulla Popolazione.

Dalla Zuanna, G. (2001). The banquet of Aeolus: A familistic interpretation of Italy's lowest low fertility. Demographic Research 4(5): 131-162. http://www.demographic-research.org/Volumes/Vol4/5 doi:10.4054/DemRes.2001.4.5.

De Rose, A. (1992). Socio-Economic Factors and Family Size as Determinants of Marital Dissolution in Italy. European Sociological Review 8(1): 71-91.

De Rose, A. (1999). Separazione e divorzi in Italia. Rome: Società Italiana di Statistica - Gruppo di Coordinamento per la Demografia.

De Rose, A. and Rosina, A. (1999). Scioglimento delle unioni. In: De Sandre P., Pinnelli A., and Santini A. (eds.). Nuzialità e fecondità in trasformazione: percorsi e fattori del cambiamento. Bologna: Il Mulino.

De Rose, A. and Di Cesare, M.C. (2003). Genere e scioglimento della prima unione. In: Pinnelli A., Racioppi F. and Rettaroli R. (eds.). Genere e Demografia. Bologna: Il Mulino.

De Rose, A. (2006). Changes in Living Arrangements Between Risk and Opportunities. Proceedings of the 2007 intermediate conference "Risk and Prediction" of the Italian Statistical Society.

De Sandre, P. (1980). Caratteristiche recenti dell'instabilità familiare in Italia. Studi in Onore di Paolo Fortunato. Bologna: CLEUB.

Engelhardt, A., Trappe, H. and Dronkers, J. (2002). Differences in Family Policies and the Intergenerational Transmission of Divorce: A Comparison between the former East and West Germany. Demographic Research 6(11): 295-324. http://www.demographic-research.org/volumes/vol6/1]. doi:10.4054/DemRes.2002.6.11 
Vignoli \& Ferro: Rising marital disruption in Italy and its correlates

Ferro, I. and Salvini, S. (2007). Separazione e divorzio in Italia. Le tendenze e le differenze regionali, Popolazione e Storia 1/2007: 125-155.

Goode, W. J. (1993). World Changes in Divorce Patterns. New Haven-London: University Press.

Greenstein, T. N. (1990). Marital disruption and the employment of married women. Journal of Marriage and the Family 52(3): 657-676. doi:10.2307/352932,

Greenstein, T. N. (1995). Gender ideology, marital disruption, and the employment of married women. Journal of Marriage and the Family 57(1): 31-42. doi:10.2307/353814.

Heckert, D. A., Nowak, T. C., and Snyder, K. A. (1998). The impact of husbands' and wife's relative earnings on marital distribution. Journal of Marriage and the Family 60: 690-703.doi:10.2307/353538

Hoem, B. and Hoem, J. M. (1992). Disruption of marital and non-marital unions in Sweden. In: Trussell, J., Hankinson, R. and Tilton, J. (eds.). Demographic Applications of Event History Analysis. Oxford: Clarendon Press.

Hoem, J. M. (1996). The harmfulness or harmlessness of using an anticipatory regressor: How dangerous is it to use education achieved as of 1990 in the analysis of divorce risks in earlier years?. Yearbook of Population Research in Finland 33.

Hoem, J. M. (1997). Educational gradients in divorce risk in Sweden in recent decades. Population Studies 51(1): 19-27 doi:10.1080/0032472031000149696.

Hoem, J. M. and Kreyenfeld, M. $\left(2006^{\mathrm{a}}\right)$. Anticipatory analysis and its alternatives in life-course research, Part 1: Education and first childbearing. Demographic Research 15(16): 461-484. http://www.demographic-research.org/Volumes/ Vol15/16. doi:10.4054/DemRes.2006.15.16.

Hoem, J. M. and Kreyenfeld, M. $\left(2006^{\mathrm{b}}\right)$. Anticipatory analysis and its alternatives in life-course research, Part 2: Marriage and first birth. Demographic Research 15(17): 485-498. http://www.demographic-research.org/volumes/volls/17. doi:10.4054/DemRes.2006.15.17

Hoem, J. M., Prskawetz, A., and Neyer, G. (2001). Autonomy or conservative adjustment? The effect of public policies and educational attainment on third births in Austria, 1975-96. Population Studies 55(3): 249-61. doi: $10.1080 / 00324720127700$.

Istat (2007). [Electronic resource].Www.demo.Istat.it 
Jalovaara, M. (2001). Socio-economic status and divorce in first marriages in Finland 1991-93. Population Studies 55(2): 119-133. doi:10.1080/00324720127685.

Jalovaara, M. (2003). The joint effects of marriage partners' socioeconomic positions on the risk of divorce. Demography 40(1), 67-81.doi:10.1353/dem.2003.0004.

Jenks, G. F. (1963). Generalization in Statistical Mapping. Annals of the Association of American Geographers 53:15-26 doi:10.1111/j.1467-8306.1963.tb00429.x.

Kiernan, K. and Cherlin, A. (1999). Parental divorce and partnership dissolution: Evidence from a British cohort study. Population Studies 53(1): 39-48. doi:10.1080/00324720308068.

Kravdal, Ø. and Noack, T. (1989). Like marries like -- the safest choice?. Scandinavian Population Studies 9: 243-258.

Lesthaeghe, R. (1992). The second demographic transition in Western Countries. In: Oppenheim, M. K. and Jensen, A. (eds.). Gender and family change. Oxford: Clarendon Press.

Lillard, L. A., Brien, M. J., and Waite, L. J. (1995). Premarital cohabitation and subsequent marital dissolution: a matter of self-selection. Demography 32(3): 437-57 doi:10.2307/2061690

Liu, G. and Vikat, A. (2004). Does Divorce Risk Depend on Spouses' Relative Income? A Register-Based Study of First Marriages in Sweden in 1981-1998. Rostock: Max Planck Institute for Demographic Research (MPIDR working paper; WP2004-010).

Lyngstad, T. H. (2004). The Impact of Parents' and Spouses' Education on Divorce Rates in Norway. Demographic Research 10(5): 122-140. http://www.demographic-research.org/volumes/vol10/5. doi:10.4054/DemRes.2004.10.5

Maggioni, G. (1990). La divorzialità nelle generazioni di matrimonio. In: Micheli, M. and Tulumello A. (eds.). Milano: Franco Angeli.

Maggioni, G. (1997). Separati e divorziati nell'Italia degli anni Novanta. Caratteristiche socioeconomiche e comportamenti delle generazioni. Studi Urbinati, B, lxviii.

Matysiak, A. and Vignoli, D. (2008). Fertility and Women's Employment: A MetaAnalysis. European Journal of Population 24(4): 363-384. doi:10.1007/s10680007-9146-2. 
Matysiak, A. and Vignoli, D. (forthcoming). Family and Work Re-Conciliation: A New Approach to an Old Problem. In: Kuhn, M. and Ochsen, C. (eds.). Labour Markets and Demographic Change. VS Verlag.

Micheli, G. A. (2000). Kinship, Family and Social Network: The anthropological embedment of fertility change in Southern Europe. Demographic Research 3(13). http://www.demographic-research.org/volumes/vol3/13 doi:10.4054/DemRes.2000.3.13

Moore, K. A. and Waite, L. J. (1981). Marital dissolution, early motherhood and early marriage. Social Forces 60(1): 20-40. doi:10.2307/2577930

Oláh, L. Sz. (2001). Gender and family stability: dissolution of the first parental union in Sweden and Hungary. Demographic Research 4(2): 29-96.

http://www.demographic-research.org/Volumes/Vol4/2 d01:10.4054/DemRes.2001.4.2.

Ongaro, F. (2002). Low fertility in Italy between explanatory factors and social and economic implications: consequences for the research. Proceedings of the XLI Annual Meeting of the Italian Statistical Society, Plenary and Invited sessions, 5-7 June. Padua: CLEUP.

Ono, H. (1998). Husbands' and wives' resources and marital dissolution. Journal of Marriage and the Family 60: 674-689.doi:10.2307/353537.

Oppenheimer, V. K. (1997). Woman's employment and the gain to marriage: the specialization and trading model. Annual Review of Sociology 23: 431-453. doi:10.1146/annurev.soc.23.1.431.

Oranization for Economic Co-peration and Development Employment Outlook. (2005). [Electronic resource].wWw.oecd.com

Poortman, A.-R. and Kalmijn, M. (2002). Women's Labour Market Position and Divorce in the Netherlands: Evaluating Economic Interpretations of the Work Effect. European Journal of Population 18(2): 175-202. do1:10.1023/A:1015520411449.

Preston, S. H. (1986). Changing values and falling birth rates. Population and development review, supplement n.12: 176-195.

Reher, D. S. (1998). Family ties in Western Europe: persistent contrasts. Population and Development Review 24: 203-234 doi:10.2307/2807972

Ross, H. L. and Sawhill, I. V. (1975). Time of transition. Washington: The Urban Institute. 
Santini, A. (1992). Analisi demografica. Fondamenti e metodi. Firenze: La nuova Italia.

Sayer, L. C. and Bianchi, S. M. (2000). Woman's economic independence and the probability of divorce. A review and re-examination. Journal of Family Issues 21(7): 906-943 doi:10.1177/019251300021007005.

Sgritta, G. B. (1993). Divorzio. In: Enciclopedia delle scienze sociali. Rome: Istituto dell'Eciclopedia italiana: 231-242.

Spitze, G. and South, S. J. (1985). Woman's employment, time expenditure, and divorce. Journal of Family Issues 6(3): 307-329. doi:10.1177/019251385006003004.

Tomassini, C. Wolf, D. A. and Rosina, A. (2003). Parental housing assistance and parent-child proximity in Italy. Journal of marriage and family 65: 700-715. doi:10.1111/j.1741-3737.2003.00700.x.

Trussell, J. Rodriguez, G. and Vaughan, B. (1992). Union Dissolution in Sweden. In: Trussell, J., Hankinson, R. and Tilton, J (eds.). Demographic Applications of Event History Analysis. Oxford: Clarendon Press.

Tzeng, J. and Mare, R. D. (1995). Labour market and socio-economic effect on marital stability. Social Science Research 24: 329-351 doi:10.1006/ssre.1995.1013

van de Kaa, D. (1987). Europe's second demographic transitino. Population Bollettin 42(1). Washington: Population Reference Bureau.

Weiss, Y. and Willis, R. J. (1997). Match quality, new information, and marital dissolution. Journal of Labor Economics 15: S293-S329. doi:10.1086/209864.

White, L. K. (1990). Determinants of divorce: A review of research in the eighties. Journal of Marriage and the Family 52:904-912. doi:10.2307/353309.

Zanatta, A. L. (1997). Le nuove famiglie. Bologna: Il Mulino. 
Vignoli \& Ferro: Rising marital disruption in Italy and its correlates 